\title{
A 'Joined-Up' Electronic Journal Service: User Attitudes and Behaviour
}

\section{Ken Eason ${ }^{1}$ Ross MacIntyre ${ }^{2}$ and Ann Apps ${ }^{3}$}

${ }^{1}$ The Bayswater Institute, 9 Orme Court, London W2 4RL 0+44 (0)207 229 2729, k.d.eason@lboro.ac.uk

${ }^{2}$ MIMAS Service, Manchester Computing, The University of Manchester Oxford Road, Manchester, M13 9PL, UK

+44(0)161 275 7181, ross.macintyre@manchester.ac.uk

${ }^{3}$ MIMAS Service, Manchester Computing, The University of Manchester, Oxford Road, Manchester, M13 9PL, UK

+44(0) 161275 6039, ann.apps@ manchester.ac.uk

\begin{abstract}
Studies are reported of user attitudes and behaviour with the Zetoc service before and after the implementation of a 'joined-up' service using OpenURL technology. Positive attitudes translated into active usage in some circumstances but not others. Four strategies are identified by which users identify articles of interest and obtain full text. A model of user behaviour is advanced to explain the factors that mediate attitudes and behaviour. The model depicts usage as dependent on the effectiveness of the 'joined-up' service delivery for each user and on the way in which users add useful facilities to their 'ready to hand' current practices.
\end{abstract}




\section{From attitudes to usage}

This paper is an exploration of what happens when a service is provided that users have said they want. We have been able to study users who have the opportunity to go seamlessly from electronic discovery of an article title to its full electronic text, an opportunity many of them had been asking for. We might expect that, where attitudes are positive, there would be a rapid take-up of the service. However, attitude research has consistently found that a positive attitude does not necessarily translate into action. In the information systems domain we might hypothesise, for example, that there are many barriers that might prevent usage developing.

A model of user behaviour that has stimulated much user attitude research in relation to the use of information systems is the TAM - the Technology Acceptance Model (Davies 1983). This relatively simple model depicts attitudes towards using a service as the product of perceived benefits (the 'pull') and perceived ease of use problems (the barriers to use). Many attitude surveys have been inspired by the TAM to explore the benefits and barriers that shape attitudes to specific services. For example, studies of user attitudes to internet shopping have demonstrated that perceived benefits are tempered by concerns over the trust users can have in handing over financial information.

TAM researchers have focused on the the factors that affect attitudes rather than the usage patterns that result. They have not looked at what gets used and how usage develops over time. But we know from many studies that usage of a service is often very selective. A study of branch banking staff, for example, found that most clerks used only 5 of the 36 features of a service that gave them access to information in a customer's account (Eason 1984). Similarly a study of the use of telephone \#* services showed that users typically used only one or two of the many services available (Eason and Damodaran 1986). Why do users select some features and ignore others? We have had an opportunity to follow the attitudes and usage patterns of the users of a major bibliographic record system over a four year period. As a result we have been able to follow the way attitudes have translated into behaviour and the factors that have influenced the translation.

\section{The Zetoc service}

Since its launch in September 2000, the Zetoc service (http://zetoc.mimas.ac.uk) has become a popular electronic resource for UK academics and others who need to keep up-to-date with developments in their field of study. It provides table of contents information for the journals and conference proceedings held by the British Library, a database that currently includes more than 25 million records. It is funded by the Joint Information Systems Committee (JISC) and provides free access to staff at UK Universities and is provided by MIMAS at the University of Manchester. In its initial form the service provided 22 facilities that enabled users to undertake a variety of activities: 
- Access via the Zetoc website to search the British Library database

- Z39.50 facilities to transfer records to bibliographic systems such as EndNote

- Email alerts - to receive Table of Contents details of new issues of selected journals etc

- Ordering facilities - Inter-Library Loans and other routes by which the user can order a printed copy of the full text of an article.

In its first two years the service became very popular. By 2002 there were 12,394 users registered to receive email alerts and approximately 40,000 searches of the database each month.

\section{Evaluating the Zetoc sevice}

Evaluating the user response to the Zetoc service has been conducted in four ways. Macro information has been obtained from the usage logs of different facilities at each institution. Unfortunately this information cannot be linked to individual user behaviour and to study this two electronic questionnaires have been distributed to users. Finally an interview study has been undertaken to provide qualitative information. This paper focuses on the interview study because it provides richer information on the usage behaviour of users. However, a summary of the results of the $\log$ data and the questionnaire studies is presented below to provide a broad context within which the interview data can be placed. Further details of the questionnaire surveys are provided in Eason et al (2004) and Eason et al (2005).

\subsection{The initial survey}

During 2001 the first evaluation of user responses to Zetoc was conducted. An electronic questionnaire attracted 655 responses from over 100 higher education institutions. The questionnaire sought evidence of usage and of attitudes. Usage was explored by asking users which of the 22 facilities in the system they had used. Attitudes were examined by asking what features were valuable in the current service, and what hopes they had for the future development of the service. The results showed that $83 \%$ of the sample (the 'passive majority') used from 1 to 5 of the features available. Most of them thought of Zetoc as a British Library email alert service and made little use of the rest of the facilities. The remaining 17\% used from 6 to 18 of the facilities. We called them the 'active integrators' because they were busy linking what they could do with Zetoc with other services they used.

The users were mainly academics, researchers, post-graduate students and librarians and there were significantly more post-graduates and librarians amongst the 'active integrators'. The attitudes towards Zetoc were very positive; it was seen as a single resource that enabled users to keep up-to-date with broad areas of interest. The average number of journal alerts was 13 per user but many set far more. The biggest disappointment was that, when an article of interest was found, there was no way within the system to get electronic full text. The service had features for ordering printed copies of articles but these were rarely used. When they found an article of interest, users left the service to get full text. The major hope for the future was that the service would be able to provide a direct route from an article title to full text on their desk-top: they wanted a joined-up electronic service. 


\subsection{Studying the use of 'joined up' facilities}

From 2002 onwards a series of enhancements that implemented OpenURL Technology in Zetoc made electronic join-up a reality. This technology enables direct communication between two services and made possible two changes to the Zetoc service. First, University libraries with Metasearch portals, which enable federated searching across their resources, could provide their users with direct access to the Zetoc database without the need to access the Zetoc website. The opportunity to use this method to search the database led to a rapid increase in usage leading to 46,229 searches in March 2005. Secondly, OpenURL technology makes it possible for Zetoc to link directly to electronic full texts or abstracts of articles held by other services. A 'more information' about a selected article feature was included in Zetoc to tell users what electronic or otherwise information is available and it may be able to provide direct access to it. The use of this service has grown from 4,954 (November 2002) to 13,306 in March 2005. This service operates in two ways. When a University registers with Zetoc its OpenURL 'resolver', which may possibly but not necessarily be part of a Metasearch portal, the 'more information' feature is able to list for a user the specific resources that can provide the full text of, and other services relating to, an article, which are available to a user at that University. When the University does not have an OpenURL resolver a 'default' service shows the user where an electronic abstract or full text is available but it cannot tell whether the user will be able to access them. Use of 'more information' in the default mode has been more or less stable since 2003 at 9,000 per month but, as more Universities register their resolver with Zetoc, the use of the OpenURL resolver route has grown from 594 in March 2003 to 4,625 in March 2005. In a relatively short period the use of these facilities at a particular group of institutions has increased significantly.

A second questionnaire survey was undertaken in 2003 to examine how usage had changed with the implementation of these enhancements and to assess changes in attitudes to Zetoc. It yielded 167 responses. It was followed by an interview study of 26 users. Both samples were questioned about the benefits they sought from Zetoc. Top of the list was being able to keep up-to-date across many journals and second was the hope that they would be able to get from the title of an article to electronic full text. Of these 193 users, $118(61 \%)$ were aware of the enhancements to the service and they had made some use of these services. Of this group $79(67 \%)$ thought the service was 'better', $34(29 \%)$ that it was 'the same' and 5 (4\%) 'worse'. Those who considered the service had improved included $93 \%$ of users at universities with their own resolvers and $81 \%$ of users at the older, more established universities. Those who said it had not improved, included $53 \%$ of the users at newer universities and colleges, most without their own resolvers.

Three factors seem to explain these differences:-

- Many 'passive' users had not noticed the new facilities and had not used them.

- Some users are achieving their dream of a seamless route to electronic full text one user called it 'magic'. They were successful for one of two reasons. First if they were at a large, established university with many subscriptions to electronic journal resources they often got access to the articles they wanted. Second, if their university had a resolver linked to Zetoc, they were told whether they could get electronic full text. 
- Some users are looking for electronic full text but are not being so successful. The user of the default 'more information' facility may be told of a source of full electronic text but may not be allowed access. This happened in particular when their institution had limited subscriptions to electronic resources. Some users in the survey had been disappointed sufficient times to be developing negative attitudes to the service. The promise of electronic full text was proving an illusion.

Users in all these categories had expressed positive views about the seamless delivery of full text but, now it was available, were reacting in different ways. It was clear that the context in which they were using the service was having a powerful effect and to examine this in greater detail we undertook an interview study.

\subsection{Examining user strategies}

Interviews were conducted at six universities, three of which had resolvers linked to Zetoc and three that did not. The interviews obtained structured information about the use of Zetoc but explored in an unstructured way the strategy the user employed to locate relevant information and obtain full text. From the data the use of Zetoc could be placed in the context of the other services the users made use of. Twenty-six interviews were conducted, sufficient to identify a number of different strategies if not to provide statistical evidence of their occurrence in the population at large. Table 1 summarises the strategies and their occurrence in the different universities.

Table 1: User Strategies

\begin{tabular}{|c|c|c|c|c|c|c|}
\hline \multirow{2}{*}{$\begin{array}{l}\text { Universities } \\
\text { User Strategy }\end{array}$} & \multicolumn{2}{|c|}{$\begin{array}{c}\text { With resolver } \\
3\end{array}$} & \multicolumn{2}{|c|}{$\begin{array}{c}\text { Without resolver } \\
3 \\
\end{array}$} & \multicolumn{2}{|c|}{$\begin{array}{c}\text { Total } \\
6\end{array}$} \\
\hline & No. & $\begin{array}{l}\text { Av. zetoc } \\
\text { score }\end{array}$ & No. & $\begin{array}{r}\text { Av. zetoc } \\
\text { score }\end{array}$ & No. & $\begin{array}{r}\text { Av. zetoc } \\
\text { score }\end{array}$ \\
\hline Passive: ad hoc & 2 & 1.8 & 3 & 1.7 & 5 & 1.7 \\
\hline Passive: traditional & 1 & 7.0 & 3 & 6.1 & 4 & 6.5 \\
\hline Active: fragmented & 7 & 7.5 & 4 & 5.5 & 11 & 6.5 \\
\hline Active: integrated & 6 & 10.0 & 0 & 0 & 6 & 10.0 \\
\hline Total & 16 & 7.6 & 10 & 5.9 & 26 & 6.9 \\
\hline
\end{tabular}

The sample included nine users who adopted a passive strategy, i.e. they had existing ways of getting information and were not actively looking for other methods. The 'passive: ad hoc' users had low zetoc scores, i.e. used very few facilities; mostly they had set up some email alerts and 'let the system do its work'. Often they could not find the time to follow up the emails. These users were typically academics with many pressing duties. As one reported 'the emails tyrannise me; they come when I cannot follow them up and I'm left feeling guilty and out of touch'. The 'passive: traditional' users were more organised about looking for new articles which they did mostly by traditional means such as visiting the library. However, they were not looking for new services.

Users with passive strategies were present in universities with or without resolvers. It is likely that these strategies are as prevalent in the population as the passive users in the first survey. They are less well represented in the interview sample because it 
proved hard to get people to agree to be interviewed on things they make little or no use of.

There were two strategies by which users were actively seeking to make more use of electronic resources. Both made use of the enhanced facilities and exhibited quite high Zetoc scores. The first strategy we have labelled 'active: fragmented' because users already used a range of electronic resources - both for discovery and for getting full text - and they added particular links via Zetoc when they found they worked. They were building idiosyncratic electronic library facilities for themselves in a rather happenstance way. These users were evenly split between institutions with and without resolvers and used whatever worked for each journal of interest. This is the group that expressed most frustration when they located electronic resources that they could not access. The final group were all at large established universities with a resolver linked to Zetoc and considerable electronic resources. We have called this strategy 'active: integrated' because, as a result of regular success in using Zetoc the users had built it into their routine of keeping up-to-date. Some research students were, for example, using the service to compile an electronic full text library of the articles they needed for their research.

\subsection{From attitude to usage revisited}

These evaluations confirm the central tenet of the Technology Acceptance Model that a positive attitude to benefits and relative ease of use will lead to usage of a service. There are many users for whom the zetoc enhancements are helping to make the integrated electronic library a reality and they have enthusiastically embraced the new facilities. There are many others, however, whose positive attitudes have been tempered by a variety of barriers to usage. There are two kinds of barrier, those related to service delivery and those related to the working practices of the users' themselves.

4.1 Service Delivery Barriers. The providers of Zetoc can set up a route from discovery to delivery of electronic full text but cannot control whether it will work for a particular user in a particular location. The integrated electronic library is a product of many services working together and success for a user depends also on the electronic subscriptions of the host institution, the links made by the host to the Zetoc service and the service offering the relevant full text article. When all these services work together the result may be the 'magic' experience of getting from discovery to full text 'in a few clicks'. When it does not work well the user may have a fruitless and time wasting experience and this may discourage further use of these facilities. It may also harden attitudes on the basis that the electronic library is more myth than reality.

4.2 The Barrier of Existing Working Practices. At any one institution there are wide variations in usage behaviour and to explain this we have to understand the context within which each user operates. What is most evident from the user interviews is that every user has established a set of methods and resources by which they keep up-to-date in their domain of study. These may be paper based or electronic and they may be more or less efficient but they are above all what Winograd and Flores (1987) call 'ready-to-hand'. This is a concept from the philosopher Heidegger (1977) that emphasises the way in which people undertake their everyday tasks by using tools and techniques that are so familiar to them that they do not have to think 
about them. They can then concentrate on the job in hand. Most users are not in the business of regularly reviewing how they get information and whether there are new services that might help them. This is particularly so for the 'passive users' who are probably in the majority in the Zetoc population and who have mostly yet to explore the 'join-up' facilities.

If existing working practices dominate user behaviour, what then leads to the exploration of new opportunities? There appear from the interview data to be two basic routes. The first is what Winograd and Flores (again borrowing from Heidegger) call the 'breakdown' - when something goes wrong or is a little different from the normal. The user is then pushed to explore beyond their usual practice. They still have a task goal to achieve which means they will not want to stray far. In the case of Zetoc the reason so many quickly discovered the new facilities was that in the normal course of following up a reference they found on their screens a 'more information' facility. It was an easy step to try it and if it worked a great new and available facility was immediately 'ready to hand'. If it did not work, and a time wasting diversion ensued, the further use of the facility might be in question. The important consequence of this way of learning about a new service is that it is fragmentary. The user explores one facility on a particular occasion - it is not a systematic exploration of all that Zetoc has to offer - and it explains why people add incrementally to their working practice rather than make a full evaluation of what is available.

The second route that some of the more active users took was to attend a course on Zetoc or otherwise study the new service as a whole. There is some evidence that librarians and research students often took this route. These are users who for professional or advanced training reasons were prepared to give time to understand new electronic resources. Unfortunately, this group is a minority; the more likely route to greater use of electronic resources is the localised examination of a particular facility for a particular purpose.

\section{Conclusions}

Although the focus of this research has been the Zetoc service, our attempts to understand user behaviour have focused on the place it has in the array of services that are the users' 'ready to hand' working practices. Although the TAM reflects the major benefits and barriers that shape attitudes it says little about the mechanisms by which some facilities become used and others do not and why some users make restricted usage whilst others are much more active. The rapid growth of the use of Zetoc for seamless access to electronic full text in some places but not others has revealed some of the mechanisms by which positive attitudes are or are not transformed into usage. First, the local service delivery can make this a rewarding or a frustrating experience. Second, and perhaps of greatest significance, most users will only try new services as minor variations on normal practice that are easy to explore. They will then make a comparative evaluation against normal practice in a particular instance and, if this is successful, will add this increment to their practice. An interesting challenge for developers is how to deliver what are for them complete systems but for users are a source of add-ons to the resources they use.

\section{References}


Davis, F.D. (1993) User acceptance of information technology: system characteristics, user perceptions and behavioural impacts International Journal of Man-Machine Studies, 38(3), 475-87.

Eason, K.D. (1984) Towards the Experimental Study of Usability Behaviour and Information Technology, 3(2), 133-43.

Eason K. D. and Damodaran L. (1986) Usable Customer Interfaces In Griffiths, J. (Ed.) Local Telecommunications London, Peter Peregrinus

Eason, K. D., MacIntyre, R., Apps, A., and Ashby, M. A. (2003) Early integrators and the Passive Majority: An evaluation study of a large web-based bibliographic reference database. Proceedings of the Digilib Conference, Espoo, Finland September 8-9, 2003.

Eason K., Harker S., Apps A. and MacIntyre R. (2005) Towards an Integrated Digital Library: Exploration of User Responses to a 'Joined-Up' Service Lecture Notes in Computer Science, 3232, 452 - 63

Heidegger M. (1977) The question concerning technology New York, Harper \& Row

Winograd T. and Flores F. (1987) Understanding computers and cognition Boston, Addison-Wesley 